\title{
ANALISIS BAURAN PEMASARAN (MARKETING MIX) DAN STRATEGI PENGEMBANGAN (STUDI KASUS PADA AGROINDUSTRI KOPI BUBUK CAP INTAN DI KOTA BANDAR LAMPUNG)
}

\author{
(The Analysis of Marketing Mix and Development Strategy: Case Study at Agroindustry of Intan Brand \\ Coffee Powder in Bandar Lampung City)
}

Dilla Sefa Ledy, Dwi Haryono, Suriaty Situmorang

\begin{abstract}
Jurusan Agribisnis, Fakultas Pertanian, Universitas Lampung, Jl. Prof. Dr. Soemantri Brojonegoro No. 1 Bandar Lampung 35145, Telp. 082178751291, e-mail: dillasefa15@gmail.com
\end{abstract}

\begin{abstract}
This study aims to analyze the marketing mix and development strategy which is applied to the agroindustry of Coffee Powder of Intan Brand in Bandar Lampung City. This research was conducted purposively in the agroindustry of Intan Brand Coffee Powder in determined Bandar Lampung City of Lampung Province. Data collection of this study was conducted from March to April 2017. This research is a case study, employed 14 people as respondents. The research data is analyzed by qualitative descriptive and SWOT analysis. The results of this study indicated that the marketing mix applied to the Intan Brand Coffee Powder agroindustry were (a) good quality product, (b) price determined by competitor price, (c) located at strategic place, and $(d)$ promotion activities that have been applied by Intan Brand Agroindustry Coffee Powder was by face-to-face sales and sales promotion. The development strategy of Intan Brand Coffee Powder agroindustry in Bandar Lampung City were (a) the owner of agroindustry was determining the policy on utilizing the technology, (b) utilizing the location in the market and continuing to cooperate with PTPN 7 in order to have a bigger opportunities (c) maintaining good quality product so that the product could still competing with similar business at the market, $(d)$ empowering the ability and human resource skills to resolve the limitations of capital in following technological developments.
\end{abstract}

Key words: coffee powder, development strategy, marketing mix

\section{PENDAHULUAN}

Pembangunan nasional memiliki beberapa sasaran, salah satunya adalah pembangunan ekonomi dengan menitikberatkan pada sektor pertanian. Kontribusi sektor pertanian terhadap pembangunan ekonomi dapat dilihat dari besarnya Produk Domestik Bruto (PDB) dimana sektor pertanian menyumbang sebesar 13,52 persen dari total keseluruhan PDB (Badan Pusat Statistik 2016).

Pertanian Indonesia terdiri dari berbagai macam subsektor, antara lain subsektor tanaman pangan, subsektor peternakan, subsektor perikanan, subsektor perkebunan, dan subsektor kehutanan. Salah satu subsektor pertanian yang memiliki peranan yang cukup penting adalah subsektor perkebunan, karena subsektor ini merupakan salah satu subsektor yang mendukung kegiatan industri dan meningkatkan perekonomian nasional (Badan Pusat Statistik 2015a).

Kopi merupakan salah satu komuditas unggulan subsektor perkebunan di Indonesia, karena memiliki peluang pasar, baik di dalam maupun di luar negeri. Kopi merupakan komoditas tropis utama yang diperdagangkan di seluruh dunia dengan kontribusi setengah dari total ekspor komoditas tropis (Kementerian Pertanian 2015). Kopi memiliki peranan yang cukup penting dalam meningkatkan perekonomian nasinal maupun daerah, sehingga kopi menjadi salah satu komoditas andalan Indonesia.

Perkembangan produksi tanaman kopi banyak dilakukan di semua daerah hampir di seluruh pelosok Indonesia. Salah satu daerah penghasil kopi yang terdapat di Indonesia adalah Provinsi Lampung. Provinsi Lampung merupakan sentra produksi kopi terbesar kedua di Indonesia setelah Provinsi Sumatera Selatan dan Provinsi Lampung hanya memproduksi dua jenis tanaman kopi, yaitu kopi arabika dan kopi robusta (BPS 2015b). Petani kopi di Provinsi Lampung banyak menanam kopi robusta dibandingkan dengan arabika. Hal ini disebabkan karena secara agronomis wilayah Lampung lebih cocok membudidayakan kopi robusta dibandingkan dengan arabika. 
Kopi robusta banyak dimanfaatkan oleh agroindustri sebagai produk olahan. Salah satu agroindustri kopi bubuk yang ada di Provinsi Lampung adalah Kopi Bubuk Cap Intan. Kopi Bubuk Cap Intan berdiri sejak tahun 1995, yang sudah pernah terkenal, tetapi belakangan ini hampir "terlupakan". Suatu agroindustri memiliki kecenderungan untuk bersaing dengan agroindustri lainnya. Untuk menjaga kelangsungan hidup agar dapat bertahan dalam persaingan, agroindustri Kopi Bubuk Cap Intan perlu melakukan strategi dalam menciptakan keunggulan produk untuk menarik konsumen agar beralih ke produknya. Strategi yang dapat dipilih adalah strategi pengembangan. Strategi pengembangan sangatlah penting dilakukan agar usaha tersebut dapat berkelanjutan dan tidak mengalami kemunduran.

Pemasaran memengang peranan yang cukup penting bagi keberlangsungan suatu agroindustri, dengan adanya pemasaran maka produk dapat dikenal oleh konsumen. Agar agroindustri Kopi Bubuk Cap Intan dapat memperluas pangsa pasar dan merebut pasar, maka agroindustri tersebut perlu mengetahui strategi bauran pemasaran atau tataniaga campuran (marketing mix) yang diperlukan untuk meningkatkan volume penjualan. Bauran pemasaran merupakan kombinasi antara empat unsur pemasaran, yakni produk, harga, promosi dan saluran distribusi, yang merupakan komponen yang dapat dikendalikan dan dapat digunakan oleh perusahaan untuk mepengaruhi tanggapan atau respon konsumen. Oleh karena itu, para pengusaha perlu mengetahui bagaimana kombinasi bauran pemasaran (marketing mix) yang tepat untuk diterapkan agar dapat menarik konsumen atau pelanggan sebanyak mungkin, sehingga memperoleh keuntungan yang maksimal (Kotler 2002). Tujuan dari penelitian ini adalah mengetahui bauran pemasaran yang diterapkan dalam kegiatan pemasaran, serta merumuskan strategi pengembangan yang ada pada agroindustri Kopi Bubuk Cap Intan.

\section{METODE PENELITIAN}

Metode penelitian yang digunakan adalah studi kasus. Penelitian ini dilaksanakan pada agroindustri Kopi Bubuk Cap Intan di Kota Bandar Lampung yang dipilih secara sengaja (purposive). Responden dalam penelitian mencakup 14 orang, yang terdiri dari, 1 orang pemilik, 2 orang karyawan, 3 agroindustri pesaing, PTPN 7, Dinas Koperasi, UMKM, Perindustrian dan Perdagangan Kota Bandar Lampung, 3 konsumen agroindustri Kopi Bubuk Cap Intan dan 3 konsumen kopi bubuk merek lainnya. Pengumpulan data dilaksanakan dari bulan Maret - April 2017. Metode pengumpulan data terdiri dari data primer dan data sekunder. Data primer diperoleh dari wawancara dan pengamatan langsung yang mencakup data produksi, harga, informasi pemasaran dan data lainnya yang berada di dalam agroindustri Kopi Bubuk Cap Intan yang digunakan dalam penelitian. Data sekunder diperoleh dari Badan Pusat Statistik, Kementerian Pertanian dan pustaka lainnya yang berhubungan dengan penelitian ini..

Metode analisis yang digunakan untuk menjawab tujuan pertama dan kedua adalah metode analisis deskriptif kualitatif yaitu dengan menggunakan analisis bauran pemasaran dan analisis SWOT. Metode analisis deskriptif kualitatif digunakan untuk menjawab tujuan pertama, yaitu menggunakan variabel $4 \mathrm{P}$ yang terdiri dari produk (product), harga (price), tempat (place) dan promosi (promotion). Analisis SWOT digunakan untuk menjawab tujuan kedua yaitu merumuskan strategi perusahaan dengan menggunakan matriks IFE, EFE dan diagram analisis SWOT, yang dapat dilihat dari aspek lingkungan internal dan eksternal pada agroindustri.

Penyusunan strategi pengembangan dalam penelitian ini melalui beberapa tahap. Tahap pertama, menentukan faktor-faktor lingkungan internal dan lingkungan eksternal. Tahap ke dua, pemberian bobot dan rating yang kemudian dikalikan untuk mendapatkan skor total, sehingga dapat ditentukan rangking pada masing-masing komponen menggunakan matriks IFAS (Internal Factors Analysis Summary) dan EFAS(External Factors Analysis Summary). Tahap ke tiga, menyilangkan setiap komponen dari hasil perangkingan matriks IFAS dan EFAS untuk menghasilkan strategi pengembangan. Tahap ke empat, dilakukan pembobotan terhadap strategi tersebut berdasarkan visi dan misi yang dimiliki agroindustri, sehingga diperoleh sepuluh strategi prioritas teratas berdasarkan analisis SWOT.

Penentuan bobot setiap komponen IFAS dan EFAS adalah dengan menggunakan metode derajat kepentingan relatif menurut David (2004). Penentuan bobot ini melibatkan beberapa pihak yang dijadikan responden dalam penelitian. Para responden ini menentukan komponen IFAS dan EFAS mana yang lebih dipentingkan, kurang dipentingkan, atau sama-sama dipentingkan dan kemudian akan diberi nilai 0,1 dan 2 yang dicatat pada tabel catur yang akan menghasilkan derajat 
kepentingan relatif untuk setiap komponen IFAS dan EFAS. Hasil penelitian dari setiap komponen tersebut selanjutnya dijumlahkan kemudian akan dibagi dengan skor total sehingga diperoleh bobot masing-masing komponen IFAS dan EFAS. Pembagian hasil setiap komponen dengan skor total adalah untuk memperoleh nilai keseluruhan bobot komponen berjumlah satu atau 100 persen.

Bobot masing-masing komponen IFAS dan EFAS dari 14 responden dijumlah untuk mendapatkan nilai rata-rata bobot yang akan digunakan pada matriks IFAS dan EFAS. Menurut David (2004), penentuan rating komponen IFAS dan EFAS adalah dengan cara responden memberikan nilai 14 pada setiap komponen, selanjutnya dihitung nilai modus untuk setiap komponen IFAS dan EFAS. Nilai modus tersebut yang digunakan pada matriks IFAS dan EFAS. matriks IFAS dan EFAS. Penentuan rating komponen IFAS dan EFAS adalah dengan cara responden memberikan nilai 14 pada setiap komponen, selanjutnya dihitung nilai modus untuk setiap komponen IFAS dan EFAS. Nilai modus tersebut yang digunakan pada matriks IFAS dan EFAS.

\section{HASIL DAN PEMBAHASAN}

\section{Analisis Bauran Pemasaran}

Pemasaran adalah proses sosial yang dilakukan oleh seseorang atau sekelompok, untuk memenuhi kebutuhan dengan cara menawarkan dan mempertukarkan produk dan jasa yang memiliki nilai, sehingga dapat memberikan kepuasan yang maksimal. Di dalam pemasaran terdapat strategi pemasaran yang memiliki peranan penting dalam mempengaruhi konsumen untuk melakukan pembelian suatu produk atau jasa yang sering disebut sebagai bauran pemasaran (marketing mix). Menurut Kotler (2005) bauran pemasaran diklasifikasikan menjadi empat kelompok yang luas yang disebut sebagai $4 \mathrm{P}$ dalam pemasaran, yaitu produk (product), harga (price), tempat (place), dan promosi (promotion).

\section{Bauran Produk (product mix)}

Berdasarkan hasil penelitian, produk yang dihasilkan adalah berupa kopi bubuk. Kopi bubuk tersebut diberi merek Kopi Bubuk Cap Intan. Merek yang digunakan Kopi Bubuk Cap Intan telah sesuai dengan teori Saefudin (1983), yaitu pendek, mudah dieja, dibaca, sederhana, mudah diingat, enak didengar, dan tidak memberikan kesan negatif. Bentuk produk yang dihasilkan oleh Kopi Bubuk Cap Intan berupa bubuk hitam dan warna kopi bubuk tersebut sangat pekat.

Bentuk kemasan yang digunakan oleh agroindustri tersebut adalah dengan cara tradisional, yaitu menggunakan plastik transparan dengan ukuran $1 \mathrm{~kg}, 1 / 2 \mathrm{~kg}, 250$ gram, 200 gram, 100 gram dan 50 gram Kemasan tersebut berlogo Cap Intan yang disesuaikan dengan merek. Masa keawetan Kopi Bubuk Cap Intan adalah satu tahun untuk kemasan yang belum dibuka, dan $1-2$ bulan untuk kemasan yang sudah dibuka. Selain itu, pada kemasan Kopi Bubuk Cap Intan sudah terdapat label halal, sehingga konsumen merasa aman ketika mengkonsumsinya.

\section{Bauran Harga (price mix)}

Berdasarkan penelitian Epriani, Endaryanto, Indriani (2017), harga sangat menentukan keberhasilan suatu produk yang dipasarkan, karena harga merupakan hal yang sangat dipertimbangkan konsumen untuk mengkonsumsi suatu barang atau jasa. Metode penetapan harga yang ditawarkan produsen agroindustri Kopi Bubuk Cap Intan kepada konsumen adalah metode berdasarkan harga pesaing. Harga Kopi Bubuk Cap Intan yang ditawarkan kepada konsumen bermacammacam sesuai dengan ukuran kemasan.

Harga untuk kemasan 1 kg sebesar Rp50.000,00, untuk kemasan $1 / 2 \mathrm{~kg}$ sebesar Rp26.000,00, untuk kemasan 250 gram sebesar Rp13.000,00, untuk kemasan 200 gram sebesar Rp11.000,00, untuk kemasan 100 gram sebesar Rp5.500,00 dan untuk kemasan 50 gram sebesar Rp3.000,00. Harga Kopi Bubuk Cap Intan yang ditawarkan kepada pengecer adalah sebesar Rp47.000,00/kg dan Rp25.000,00 untuk kemasan $1 / 2 \mathrm{~kg}$. Cara pembayaran yang diterapkan oleh agroindustri Kopi Bubuk Cap Intan adalah tunai, dengan tujuan untuk menghindari terjadinya kerugian.

\section{Bauran Tempat (place mix)}

Lokasi penjualan Kopi Bubuk Cap Intan berada di Jl. KP Empang No. 11 Pasir Gintung, Kecamatan Tanjung Karang Pusat, Kota Bandar Lampung. Berdasarkan hasil penelitian, lokasi penjualan Kopi Bubuk Cap Intan dapat dikatakan strategis, karena lokasi penjualan mudah untuk dijangkau, dilewati oleh 
transportasi umum dan letaknya berada di pasar dan berada di tengah kota. Namun, lokasi penjualan Kopi Bubuk Cap Intan berada cukup jauh dari pabrik, sehingga membuat produsen agroindustri harus mengeluarkan biaya tambahan untuk biaya transportasi.

Saluran distribusi pada agroindustri Kopi Bubuk Cap Intan terdapat 2 jenis saluran, yaitu pertama: produsen menjual kepada konsumen akhir secara langsung, dan kedua: produsen menjual kepada pedagang pengecer. Agroindustri Kopi Bubuk Cap Intan tidak menggunakan distributor, melainkan pedagang pengecer tersebut yang datang ke tempat penjualan untuk membeli kopi bubuk tersebut, kemudian dijual ke konsumen akhir, sehingga transportasi yang digunakan untuk memindahkan kopi bubuk dari produsen ke pedagang ditanggung sendiri oleh pedagang.

\section{Bauran Promosi (Promotion Mix)}

Untuk menginformasikan ciri khas dan kelebihan-kelebihan tersebut, produsen kopi bubuk perlu melakukan bauran promosi, yaitu: periklanan, penjualan tatap muka, publisitas, dan promosi penjualan.

\section{a. Periklanan}

Agroindustri Kopi Bubuk Cap Intan belum melakukan kegiatan promosi dengan cara periklanan, dengan alasan kurangnya pengetahuan yang dimiliki pemilik maupun karyawan agroindustri dalam menggunakan teknologi dan keterbatasan modal yang dimiliki.

b. Penjualan tatap muka

Agroindustri Kopi Bubuk Cap Intan telah melakukan kegiatan promosi dengan cara penjualan tatap muka, dan biasanya produsen agroindustri Kopi Bubuk Cap Intan mempromosikannya terlebih dahulu kepada orang-orang terdekat.

c. Publisitas

Aroindustri Kopi Bubuk Cap Intan belum melakukan kegiatan promosi melalui publisitas, karena keterbatasannya modal yang dimiliki oleh agroindustri, sehingga kegiatan promosi ini belum diterapkan.

d. Promosi Penjualan

Agroindustri Kopi Bubuk Cap Intan telah menggunakan kegiatan promosi melalui promosi penjualan, yaitu dengan cara mengikuti pameran yang diadakan oleh PTPN 7.
Berdasarkan hasil penelitian, promosi yang dilakukan oleh agroindustri Kopi Bubuk Cap Intan belum diterapkan secara keseluruhan, hal ini disebabkan oleh kurangnya pengetahuan yang dalam menggunakan teknologi serta keterbatasan modal yang dimiliki oleh agroindustri tersebut.

\section{Analisis Lingkungan Internal}

Analisis lingkungan internal agroindustri Kopi Bubuk Cap Intan merupakan faktor-faktor yang berasal dari dalam agroindustri. Faktor tersebut mempengaruhi keberadaan/posisi agroindustri, maupun tindakan agroindustri baik secara langsung maupun tidak langsung. Faktor internal tersebut, terdiri dari : produk, manajemen dan pendanaan, sumber daya manusia, lokasi agroindustri, dan pemasaran. Hasil yang diperoleh dari analisis tersebut yaitu berupa faktor kekuatan dan kelemahan yang ada pada agroindustri Kopi Bubuk Cap Intan di Kota Bandar Lampung, yang dapat dilihat pada Tabel 1 dan 2.

Tabel 1. Matriks faktor internal untuk kekuatan (strenghts)

\begin{tabular}{|c|c|c|c|c|c|}
\hline Komponen & Kekuatan & Bobot & Rating & $\begin{array}{l}\text { Total } \\
\text { skor }\end{array}$ & Rank \\
\hline Produk & $\begin{array}{l}\text { Produk yang } \\
\text { dihasilkan } \\
\text { berkualitas }\end{array}$ & $\begin{array}{c}0,32 \\
1\end{array}$ & 4 & 1,284 & 1 \\
\hline $\begin{array}{l}\text { Manajemen } \\
\text { dan } \\
\text { Pendanaan }\end{array}$ & $\begin{array}{l}\text { Pemilik } \\
\text { merupakan } \\
\text { pengelola yang } \\
\text { mengatur } \\
\text { manajemen } \\
\text { agroindustri }\end{array}$ & $\begin{array}{c}0,12 \\
9\end{array}$ & 3 & 0,387 & 5 \\
\hline $\begin{array}{l}\text { Sumber } \\
\text { Daya } \\
\text { Manusia }\end{array}$ & $\begin{array}{l}\text { Keterampilan } \\
\text { yang baik telah } \\
\text { dimiliki oleh } \\
\text { sumber daya } \\
\text { manusia }\end{array}$ & $\begin{array}{c}0,21 \\
8\end{array}$ & 3 & 0,654 & 2 \\
\hline $\begin{array}{l}\text { Lokasi } \\
\text { Usaha }\end{array}$ & $\begin{array}{l}\text { Agroindustri } \\
\text { memiliki lokasi } \\
\text { yang strategis } \\
\text { karena berada di } \\
\text { pasar }\end{array}$ & $\begin{array}{c}0,15 \\
0\end{array}$ & 3 & 0,450 & 4 \\
\hline Pemasaran & $\begin{array}{l}\text { Mengikuti } \\
\text { pameran yang di } \\
\text { adakan oleh } \\
\text { PTPN } 7 \text { dengan } \\
\text { tujuan } \\
\text { memperkenalkan } \\
\text { produknya }\end{array}$ & $\begin{array}{c}0,18 \\
2\end{array}$ & 3 & 0,546 & 3 \\
\hline
\end{tabular}

Keterangan pemberian rating: (kekuatan)

4 = Kekuatan yang dimiliki agroindustri sangat kuat

3 = Kekuatan yang dimiliki agroindustri kuat

2 = Kekuatan yang dimiliki agroindustri rendah

$1=$ Kekuatan yang dimiliki agroindustri sangat rendah 
Tabel 2. Matriks faktor internal untuk kelemahan (weaknesses)

\begin{tabular}{|c|c|c|c|c|c|}
\hline Komponen & Kelemahan & Bobot & Rating & $\begin{array}{c}\text { Total } \\
\text { skor }\end{array}$ & Rank \\
\hline Produksi & $\begin{array}{l}\text { Produksi } \\
\text { menurun jika } \\
\text { ketersediaan } \\
\text { bahan baku } \\
\text { sedikit }\end{array}$ & 0,250 & 2 & 0,500 & 3 \\
\hline $\begin{array}{l}\text { Manajemen } \\
\text { dan } \\
\text { pendanaan }\end{array}$ & $\begin{array}{l}\text { Catatan } \\
\text { pembukuan } \\
\text { yang tidak } \\
\text { baik dan } \\
\text { keterbatasan } \\
\text { modal }\end{array}$ & 0,177 & 3 & 0,532 & 2 \\
\hline $\begin{array}{l}\text { Sumber } \\
\text { daya } \\
\text { manusia }\end{array}$ & $\begin{array}{l}\text { Pekerja } \\
\text { berpendidikan } \\
\text { rendah }\end{array}$ & 0,164 & 3 & 0,491 & 4 \\
\hline $\begin{array}{l}\text { Lokasi } \\
\text { usaha }\end{array}$ & $\begin{array}{l}\text { Lokasi } \\
\text { agroindustri } \\
\text { jauh dari } \\
\text { bahan baku }\end{array}$ & 0,136 & 3 & 0,409 & 5 \\
\hline Pemasaran & $\begin{array}{l}\text { Banyaknya } \\
\text { peniruan } \\
\text { brand produk } \\
\text { Sinar Baru } \\
\text { Cap Bola } \\
\text { Dunia } \\
\end{array}$ & 0,273 & 2 & 0,545 & 1 \\
\hline \multicolumn{3}{|c|}{ Total kelemahan } & & 2,477 & \\
\hline \multicolumn{6}{|c|}{$\begin{array}{l}\text { Keterangan pemberian rating : (kelemahan) } \\
4=\text { Kelemahan yang dimiliki agroindustri sangat mudah dipecahkan } \\
3=\text { Kelemahan yang dimiliki agroindustri mudah dipecahkan } \\
2 \text { = Kelemahan yang dimiliki agroindustri sulit dipecahkan } \\
1 \text { = Kelemahan yang dimiliki agroindustri sangat sulit dipecahkan }\end{array}$} \\
\hline
\end{tabular}

Berdasarkan Tabel 1 dapat diketahui bahwa kekuatan paling besar yang dimiliki agroindustri kopi Bubuk Cap Intan terletak pada komponen produk dengan skor 0,321 dan rating 4 , dimana hal tersebut menunjukkan bahwa produk yang dihasilkan agroindustri ini berkualitas yang dijadikan kekuatan bagi agroindustri Kopi Bubuk Cap Intan.

Berdasarkan Tabel 2 dapat diketahui bahwa kelemahan yang paling besar yang dimiliki oleh agroindustri Kopi Bubuk Cap Intan terletak pada komponen produk dengan skor 0,281 dan rating 3, dimana hal tersebut menunjukkan bahwa produk Kopi Bubuk Cap Intan kurang dikenal oleh masyarakat, hal ini menjadikan suatu kelemahan dalam agroindustri tersebut.

\section{Analisis Lingkungan Eksternal}

Analisis lingkungan eksternal agroindustri Kopi Bubuk Cap Intan merupakan faktor-faktor yang berasal dari luar agroindustri, Faktor tersebut mempengaruhi keberadaan/posisi agroindustri, baik secara langsung maupun tidak langsung. Faktor eksternal dari agroindustri Kopi Bubuk Cap
Intan yaitu ekonomi,sosial dan budaya, teknologi, pesaing, kebijakan pemerintah, dan konsumen. Hasil yang diperoleh dari analisis tersebut yaitu berupa faktor peluang dan ancaman yang ada pada agroindustri Kopi Bubuk Cap Intan di Kota Bandar Lampung, yang dapat dilihat pada Tabel 3 dan 4.

Berdasarkan Tabel 3 dapat diketahui bahwa peluang yang paling besar yang dimiliki oleh agroindustri kopi Bubuk Cap Intan adalah komponen konsumen dengan skor 0,545, dimana banyaknya konsumen yang menyukai kopi bubuk merupakan sebuah peluang bagi agroindustri Kopi Bubuk Cap Intan. Hal ini sejalan dengan penelitian Ariesta, Lestari, Sayekti (2016) yang mengungkapkan bahwa komponen konsumen merupakan komponen peluang terbesar bagi agroindustri skala kecil dengan skor 1,05.

Tabel 3. Matriks faktor eksternal untuk peluang (opportunities)

\begin{tabular}{|c|c|c|c|c|c|}
\hline Komponen & Peluang & Bobot & Rating & $\begin{array}{l}\text { Total } \\
\text { skor }\end{array}$ & Rank \\
\hline $\begin{array}{l}\text { Ekonomi, } \\
\text { sosial dan } \\
\text { budaya }\end{array}$ & $\begin{array}{l}\text { Kopi } \\
\text { diminati } \\
\text { oleh } \\
\text { berbagai } \\
\text { lapisan } \\
\text { masyarakat }\end{array}$ & 0,165 & 3 & 0,495 & 3 \\
\hline .Teknologi & $\begin{array}{l}\text { Pemanfaata } \\
\mathrm{n} \text { teknologi } \\
\text { yang telah } \\
\text { modern }\end{array}$ & 0,226 & 2 & 0,452 & 4 \\
\hline Pesaing & $\begin{array}{l}\text { Memiliki } \\
\text { kerjasama } \\
\text { dengan } \\
\text { PTPN } 7 \\
\text { sehingga } \\
\text { menjadi } \\
\text { peluang } \\
\text { yang lebih } \\
\text { besar }\end{array}$ & 0,172 & 3 & 0,516 & 2 \\
\hline $\begin{array}{l}\text { Kebijakan } \\
\text { pemerintah }\end{array}$ & $\begin{array}{l}\text { Memanfaatk } \\
\text { an } \\
\text { dukungan } \\
\text { dari } \\
\text { pemerintah }\end{array}$ & 0,165 & 2 & 0,330 & 5 \\
\hline Konsumen & $\begin{array}{l}\text { Banyaknya } \\
\text { konsumen } \\
\text { yang } \\
\text { menyukai } \\
\text { kopi bubuk }\end{array}$ & 0,273 & 2 & 0,545 & 1 \\
\hline
\end{tabular}

Keterangan pemberian rating : (peluang)

4 = Peluang yang dimiliki agroindustri sangat mudah diraih

$3=$ Peluang yang dimiliki agroindustri mudah diraih

$2=$ Peluang yang dimiliki agroindustri sulit diraih

$1=$ Peluang yang dimiliki agroindustri sangat sulit diraih 
Tabel 4. Matriks faktor eksternal untuk ancaman (treaths)

\begin{tabular}{|c|c|c|c|c|c|}
\hline Komponen & Ancaman & Bobot & Rating & $\begin{array}{l}\text { Total } \\
\text { skor }\end{array}$ & Rank \\
\hline $\begin{array}{l}\text { Ekonomi, } \\
\text { sosial dan } \\
\text { budaya }\end{array}$ & $\begin{array}{l}\text { Kenaikan } \\
\text { harga BBM } \\
\text { mempengar } \\
\text { uhi biaya } \\
\text { produksi }\end{array}$ & 0,164 & 3 & 0,493 & 3 \\
\hline Teknologi & $\begin{array}{l}\text { Perkemban } \\
\text { gan } \\
\text { teknologi } \\
\text { sulit di ikuti } \\
\text { karena } \\
\text { memerluka } \\
\text { n biaya } \\
\text { yang cukup } \\
\text { tinggi }\end{array}$ & 0,171 & 2 & 0,343 & 5 \\
\hline Pesaing & $\begin{array}{l}\text { Banyaknya } \\
\text { pesaing } \\
\text { sejenis } \\
\text { yang masuk } \\
\text { ke pasar }\end{array}$ & 0,307 & 2 & 0,614 & 1 \\
\hline $\begin{array}{l}\text { Kebijakan } \\
\text { pemerintah }\end{array}$ & $\begin{array}{l}\text { Kurangnya } \\
\text { pengawasa } \\
\text { n dari } \\
\text { pemerintah }\end{array}$ & 0,164 & 3 & 0,493 & 2 \\
\hline Konsumen & $\begin{array}{l}\text { Banyaknya } \\
\text { produk kopi } \\
\text { bubuk } \\
\text { merek lain } \\
\text { yang di } \\
\text { tawarkan } \\
\text { kepada } \\
\text { konsumen }\end{array}$ & 0,193 & 3 & 0,579 & 4 \\
\hline Total Anc & & \multicolumn{4}{|c|}{2,521} \\
\hline
\end{tabular}

Keterangan pemberian rating : (ancaman)

$4=$ Ancaman yang sangat mudah untuk diatasi

$3=$ Ancaman yang mudah diatasi

$2=$ Ancaman yang sulit diatasi

$1=$ Ancaman yang sangat sulit diatasi

Berdasarkan Tabel 4 dapat diketahui bahwa ancaman yang paling besar yang dimiliki oleh agroindustri Kopi Bubuk Cap intan terletak pada komponen pesaing dengan skor 0,614, dimana banyaknya pesaing sejenis yang masuk kepasar membuat positioning merek Kopi Bubuk Cap Intan tidak begitu kuat dimata konsumen. Hal ini sejalan dengan penelitian Laisa, Sayekti, dan Nugraha (2013) yang mengungkapkan bahwa komponen pesaing merupakan komponen ancaman terbesar bagi industri pengolahan ikan teri nasi kering di Pulau Pasaran, Kecamatan Teluk Betung Barat, Kota Bandar Lampung dengan skor sebesar 0,60.

Berdasarkan total skor faktor internal dan eksternal,maka dapat dibuat diagram matriks I-E yaitu dengan mencari titik potong sumbu $X$ dan sumbu Y. Titik potong sumbu X (W-S) diperoleh dari selisih antara total faktor kekuatan dan kelemahan yaitu $+0,635$ dan titik potong sumbuY
(O-T) diperoleh dari selisih antara total factor peluang dan ancaman yaitu $-0,185$.

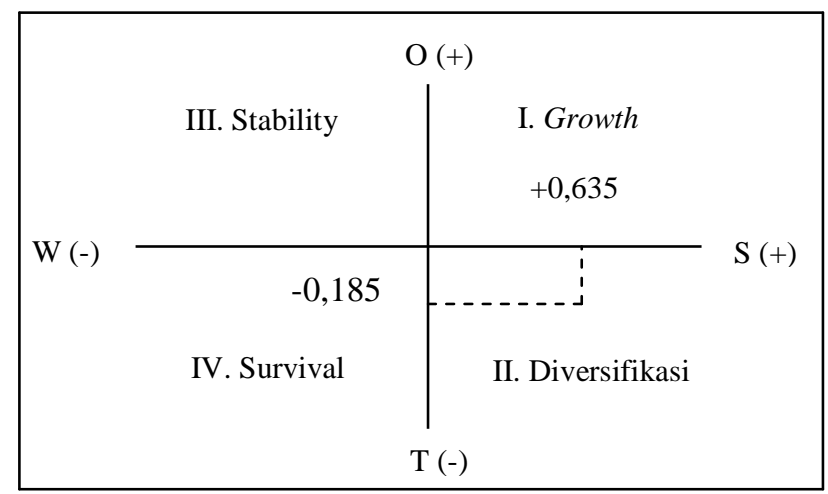

Gambar 1. Diagram SWOT faktor internal dan eksternal agroindustri Kopi Bubuk Cap Intan

Diagram internal ekstenal (I-E) dapat dilihat pada Gambar 1. Berdasarkan diagram SWOT pada Gambar 1 menunjukkan bahwa agroindustri berada pada kuadran II (diversifikasi strategi). Artinya organisasi dalam kondisi mantap, namun menghadapi sejumlah tantangan berat sehingga diperkirakan roda organisasi akan mengalami kesulitan untuk terus berputar bila hanya bertumpu pada strategi sebelumnya. Oleh karena itu, organisasi disarankan untuk segera memperbanyak ragam strategi taktisnya (David 2002).

\section{Strategi Pengembangan}

Strategi prioritas diperoleh dengan cara menyilangkan faktor internal dengan faktor ekstenal yaitu $(\mathrm{S}><\mathrm{O}), \quad(\mathrm{S}><\mathrm{T}), \quad(\mathrm{W}><\mathrm{O})$ dan $(\mathrm{W}><\mathrm{T}$ ) yang akan menghasilkan 100 strategi, selanjutnya dari 100 strategi tersebut akan dipilih sepuluh strategi menurut urutan prioritas yang diperoleh dari perangkingan dengan pendekatan visi misi agroindustri. Namun pada agroindustri Kopi Bubuk Cap Intan belum terdapat visi dan misi, sehingga visi dan misi yang digunakan pada penelitian ini untuk menentukan strategi prioritas yaitu visi dan misi Dinas Koperasi, UMKM, Perindustrian dan Perdagangan Kota Bandar Lampung. Visi Dinas Koperasi, UMKM, Perindustrian dan Perdagangan Kota Bandar Lampung adalah terwujudnya Kota Bandar Lampung sebagai daerah industri maju. Misi Dinas Koperasi, UMKM, Perindustrian dan Perdagangan Kota Bandar Lampung adalah :

1) Meningkatkan pertumbuhan dan perkembangan unit-unit usaha industri kecil, menengah, besar dan industri-industri andalan 
2) Meningkatkan pelayanan terhadap pelaku usaha industri

3) Meningkatkan pembinaan, pengawasan dan pengendali industri agar tercipta sinergitas antar industri, tenaga kerja dan lingkungan

4) Meningkatkan perekonomian dan kesejahteraan masyarakat

Strategi prioritas usaha bagi agroindustri Kopi Bubuk Cap Intan adalah :

(1) Pemilik agroindustri menentukan kebijakan dalam memanfaatkan teknologi yang digunakan.

(2) Memanfaatkan lokasi yang berada di pasar dan terus bekerjasama dengan PTPN 7 sehingga dapat memiliki peluang yang lebih besar dibandingkan pesaing.

(3) Meningkatkan kualitas produk yang dihasilkan agar mendapatkan keuntungan maksimal sehingga perkembangan teknologi dapat di ikuti.

(4) Mempertahankan kualitas produk yang baik agar produk tetap dapat bersaing dengan pelaku usaha sejenis yang masuk ke pasar.

(5) Memberdayakan kemampuan dan keterampilan SDM untuk mengatasi keterbatasan modal dalam mengikuti perkembangan teknologi.

(6) Memanfaatkan lokasi penjualan yang berada di pasar untuk mendapatkan keuntungan yang maksimal sehingga perkembangan teknologi dapat diikuti.

(7) Mengikuti pameran yang diadakan oleh PTPN 7 dengan tujuan memperkenalkan produknya guna mendapatkan keuntungan maksimal sehingga perkembangan teknologi yang memerlukan biaya yang tinggi dapat diikuti.

(8) Memperkenalkan produk kopi bubuk Cap Intan kepada masyarakat untuk meningkatkan volume penjualan sehingga dapat mengadopsi teknologi baru.

(9) Menerapkan media sosial sebagai media promosi dengan tujuan meningkatkan volume penjualan sehingga dapat mengadopsi teknologi baru.

(10) Meningkatkan kualitas produk yang dihasilkan dengan memanfaatkan dukungan dan pengawasan yang diberikan oleh pemerintah.

\section{KESIMPULAN}

Strategi bauran pemasaran yang diterapkan oleh agroindustri Kopi Bubuk Cap Intan di Kota Bandar Lampung adalah: a. Produk

Produk yang dihasilkan oleh agroindustri Kopi Bubuk Cap Intan berupa bubuk hitam, dikemas menggunakan plastik serta memiliki kualitas baik.

b. Harga

Metode penetapan harga yang ditawarkan produsen Kopi Bubuk Cap Intan yaitu berdasarkan harga pesaing.

c. Distribusi

Saluran distribusi pada agroindustri Kopi Bubuk Cap Intan di Kota Bandar lampung terdapat 2 jenis saluran yaitu :

Produsen $\rightarrow$ Pedagang Pengecer $\rightarrow$ Konsumen akhir

Produsen $\rightarrow$ Konsumen akhir

d. Promosi

Kegiatan promosi yang telah diterapkan oleh agroindustri Kopi Bubuk Cap Intan adalah dengan cara penjualan tatap muka dan promosi penjualan.

Strategi pengembangan pada agroindustri Kopi Bubuk Cap Intan di Kota Bandar Lampung, yaitu : (a) pemilik agroindustri menentukan kebijakan dalam memanfaatkan teknologi yang digunakan, (b) memanfaatkan lokasi yang berada di pasar dan terus bekerjasama dengan PTPN 7 sehingga dapat memiliki peluang yang lebih besar dibandingkan pesaing, (c) meningkatkan kualitas produk yang dihasilkan agar mendapatkan keuntungan maksimal sehingga perkembangan teknologi dapat di ikuti, (d) Mempertahankan kualitas produk yang baik agar produk tetap dapat bersaing dengan pelaku usaha sejenis yang masuk ke pasar, (e) memberdayakan kemampuan dan keterampilan SDM untuk mengatasi keterbatasan modal dalam mengikuti perkembangan teknologi.

\section{DAFTAR PUSTAKA}

Andika MS. 2012. Kinerja usaha dan strategi pengembangan agroindustri skala kecil kopi bubuk di Kota Bandar Lampung. Skripsi. Fakultas Pertanian Universitas Lampung. Bandar Lampung.

Ariesta W, Lestari DAH, dan Sayekti WD. 2016. Strategi pengembangan usaha agroindustri Beras Siger : Studi Kasus pada Agroindustri Tunas Baru di Kelurahan Pinang Jaya Kemiling Kota Bandar Lampung. JIIA: 4(3) : 326-334. http://jurnal.fp.unila.ac.id/index.ph p/JIA/article/download/1508/13662. [27 Mei 2017].

Badan Pusat Statistik. 2016. Statistik Indonesia. Badan Pusat Statistik. Jakarta. 
Badan Pusat Statistik. 2015a. Laju Pertumbuhan Produk Domestik Bruto Atas Dasar Harga Konstan Menurut Lapangan Usaha (Persen). Badan Pusat Statistik. Jakarta.

Badan Pusat Statistik. 2015b. Produksi Perkebunan Kopi di Indonesia Menurut Provinsi. Badan Pusat Statistik Provinsi Lampung. Bandar Lampung

David FR. 2004. Manajemen Strategis. Indeks Gramedia. Jakarta.

Epriani M, Endaryanto T, dan Indriani Y. (2017). Sikap konsumen dan strategi pemasaran dua merek kopi bubuk di Kota Bandar Lampung. JIIA: 5(4) : 414-421. http://jurnal.fp.unila. ac.id/Index.php/JIA/article/download/1751/15 54. [21 November Mei 2017].
Kementerian Pertanian. 2015. Statistik Perkebunan Indonesia Komoditas Kopi 20132015. Jakarta.

Laisa DD, Sayekti WD, dan Nugraha A. 2013. Analisis harga pokok produksi dan strategi pengembangan industri pengolahan ikan teri nasi kering di Pulau Pasaran Kecamatan Teluk Betung Barat Kota Bandar Lampung. JIIA: 1(2): 111-117. http://jurnal.fp.unila.ac.id/ index.php/JIA/article/view/237. [25 Maret 2017]

Kotler P. 2002. Manajamen Pemasaran Jilid 2. Edisi Mileniium PT Prenhallindo. Jakarta.

Kotler P. 2005. Manajamen Pemasaran. PT Indeks Kelompok Gramedia. Jakarta.

Saefudin AM. 1983. Manajemen Pemasaran. Bahan Kuliah Program Pasca Sarjanan Institut Pertanian Bogor. Bogor. 